\title{
APOPTOTIC AND NECROTIC EFFECTS OF CHITOSAN NANOPARTICLES LOADED WITH THE HONEYBEE, APIS MELLIFERA VENOM ON DIFFERENT CANCER CELL LINES
}

By

\author{
SAMAA I. EL-DEK ${ }^{1}$, MOSTAFA I. HASSAN ${ }^{2 *}$, ALY F. MOHAMED ${ }^{3}$ \\ AND ABDEL WAHAB KHALIL ABDEL WAHAB ${ }^{4}$
}

Department of Materials Science and Nanotechnology ${ }^{1}$, Faculty of Postgraduate Studies for Advanced Sciences (PSAS), Beni-Suef University, Department of Zoology and Entomology ${ }^{2}$, Faculty of Science, Al-Azhar University, Nasr City, Cairo, VACSERA ${ }^{3}$, Giza, and Department of Zoology ${ }^{4}$, Faculty of Science, Beni-Suef University, Beni-Suef 62511, Egypt ( ${ }^{*}$ Correspondence: mostafa012@gmail.com)

\section{Abstract}

Nanoparticles encapsulated with natural venoms have a considerable attention to improve illnesses therapies by overcoming toxic effects secreted by different pathogens. The present study explored conjugation of chitosan extracted from cuticle of naturally died honeybees nanoparticles (B-Cs-NPs) with the honeybee, Apis mellifera venom (BV). Detected related toxicity and anticancer potential of BV and BV loaded NPs- against Colon (CaCO-2), Larynx (HEp-2) and breast (MCF-7) cancer cell lines. The Inotropic gelation of chitosan (CS) with sodium tripolyphosphate (TPP) was the method used to prepare nanoparticles. Cytotoxic effects of BV and BV loaded NPs nanoparticles against the three cancer cell lines studied, then they were assessed using MTT stain assay. Data recorded revealed that combination of bee venom with bee chitosan nanoparticles enhanced the inhibitory effect against cancer cells studied when compared with bee venom alone. Also, it was cleared that by treating CaCO-2, HEp-2 \& MCF-7 cell lines with $\mathrm{IC}_{50}$ concentrations of BV alone and BV loaded chitosan nanoparticles, this induced apoptotic features as cell shrinking, peripheral condensation of chromatin, apoptotic bodies in late stage, nucleoli fragmentation, membrane blebbing, shrunken nucleus with some necrotic features. Control cells showed normal pathway of mitotic divisions of obvious cell membrane and nucleus when stained by (H\&E) and by visualization using inverted microscope.

Keywords: bee venom, chitosan nanoparticles, cytotoxicity, anticancer, cell lines

\section{Introduction}

The Hymenoptera are the third largest order of insects, comprising the sawflies, wasps, bees and ants. Stinging insects and the medical importance associated with their venoms are complex topics, and presentation of information pertaining to them requires the use of technical terms (Abdel-Rahman et al, 2015). Honeybee, Apis mellifera venom (BV) is composed of a variety of peptides, including melittin (a major component comprises approximately $50 \%$ of dry venom), adolapin, apamin, and mast cell degranulating (MCD) peptide (Park et al, 2004). In oriental medicine, bee venom not only used for treating rheumatoid arthritis, inflammation and pain (Son et al, 2007; Park et al, 2007), but it has anti-cancer potentials (Liu et al, 2002). Cancer is considered as a comprehensive predominant ailment that causes death in developing nations (Jemal et al,
2011; Calderon et al, 2014).The capability of many medications is often restricted by their ability to reach the target site of therapeutic action. In most cases, only a little quantity of applied dose reaches the targeted site, while the rest of the drug distributes throughout other organs of the body in accordance with its physicochemical and biochemical properties. So, the development of a drug delivery system that utilizes the pharmaceutical action of a medication while reducing its side effects in vivo is a difficult job. Recently, nanotechnology gained a wide attention of applications in the pharmaceutical manufacturing (Gupta, 2006). Because of the progress in nanotechnology, it is possible to produce drug encapsulated or entrapped nanoparticles to be used in an assortment of featuring designs (Jain, 2008). Polymers that are of chemical or natural 
origin were used to prepare microspheres (nanoparticles) (Tiyaboonchai, 2003). But, among different polymers, chitosan has considered in pharmaceutical applications (Shahbazi et al, 2008). Also, it enhanced the penetration by opening tight epithelial junctions; used to deliver of both vaccines and proteins (Van der Lubben et al, 2001a,b). Nanoparticles prepared from chitosan have been widely assessed for the delivering of polypeptides such as insulin (Avadi et al, 2010), tetanus toxoid (Vila et al, 2004), diphtheria toxoid (Mokarram and Alonso, 2006), snake venom (Sarei et al, 2013), and proteins (Xu and $\mathrm{Du}, 2003)$.

The aim of the current work was to compare between the anticancer effect of BV and $\mathrm{BV}$ nanocapsulated chitosan of the honeybee, Apis mellifera.

\section{Materials and Methods}

Raw materials: Bodies of normally died bees, Apis mellifera (Hymenoptera: Apidae) were gathered from various apiaries at spring and utilized as a crude material.

Extraction of chitin and chitosan: Died bees were dried at $60^{\circ} \mathrm{C}$ for 7 days and then subjected to successive five steps of treatment (Marei et al, 2016). (Fig. 1)

Preparation of bee chitosan Nanoparticles (B-CS-NPs) and Bee venom loaded chitosan nanoparticles (BV loaded CS-NPs): Bee Chitosan Nanoparticles were prepared by ionic gelation of bee Chitosan (B-CS) with trisodium polyphosphate (TPP). For Empty nanoparticles, $11 \mathrm{ml}$ of $0.33 \mathrm{mg} / \mathrm{ml}$ of TPP were dropwisely added during stirring at $1000 \mathrm{rpm}$ for 75 minutes, to $0.2 \mathrm{gm}$ of B-CS that was dissolved in $1 \%$ acetic acid. For bee venom loaded nanoparticles (BV loaded CSNPs), 20, 50, 100, 200, $400 \& 600 \mu \mathrm{g} / \mathrm{ml}$ of bee venom was added to chitosan solution just before adding TPP and at strong acidic $\mathrm{pH}$ (Marei et al, 2016). Both empty and loaded NPs were separated by centrifugation at $14000 \mathrm{rpm}$ for an hour, freeze dried at $40^{\circ} \mathrm{C} \& 0.05$ mbar then stored at $4{ }^{\circ} \mathrm{C} \pm 2^{\circ} \mathrm{C}$. Weight of both loaded and empty NPs was recorded.
Cell culture and in vitro cytotoxicity assay: Colon cancer (CaCO-2), larynx cancer (HEp-2) and breast cancer (MCF-7) cell lines were grown in RPMI- 1640 medium supplemented with $10 \%$ fetal bovine serum (FBS), $1 \mathrm{mM}$ sodium pyruvate, $2 \mathrm{mM} \mathrm{L-}$ glutamine \& antibiotics (penicillin 100 $\mathrm{IU} / \mathrm{ml}$, streptomycin $100 \mu \mathrm{g} / \mathrm{ml})$. The cell cultures were grown at $37^{\circ} \mathrm{C}$ under $95 \%$ a humidified air and 5\% CO2.The MTT assay was performed to assess the cytotoxicity of BV and BV loaded chitosan nanoparticles against cancer cell lines. Cells were $24 \mathrm{hrs}$ precultured in a concentration of a $1 \times 10^{4}$ cells/well in 96 tissue culture plates. Culture media were replaced by $100 \mu \mathrm{l}$ of the different tested materials. BV and nanocapsulated $\mathrm{BV}$ were added to pre-cultured plates then2 fold serially diluted. Plates were incubated for $24 \mathrm{hr}$ post treatment to permit trapped bee venom release. Treated media were removed and $50 \mu \mathrm{l}$ of MTT stain used as $0.5 \mathrm{mg} / \mathrm{ml}$ added to each well and left for $4 \mathrm{hr}$. Then $50 \mu 1$ DMSO was added to each well and absorbance was read at $570 \mathrm{~nm}$ by LERX-800 ELISA reader (Biotech, USA).

Histopathological examination: The CaCO-2, MCF-7 and HEp-2 cell lines were treated with $\mathrm{IC}_{50}$ concentrations of $\mathrm{BV}, \mathrm{B}-$ CS-NPs and BV Loaded CS-NPs, and then subjected to histological examinations to identify hisopathological changes appeared in treated cells. Negative control cells were considered (Mastropietro et al, 2015).

Slide preparation: Three cell lines were seeded in 24 wells plate $(100 \mu 1$ cell suspension of each). The $24 \mathrm{hrs}$ post seeding, cells were treated with $\mathrm{IC}_{50}$ concentration of $\mathrm{BV}$ \& BV loaded CS-NPs. Negative cell control was included. Plate was then incubated at $37^{\circ} \mathrm{C}$ for $24 \mathrm{hr}$. post incubation; cells were trypsinized, resuspended in fresh medium and centrifuged at $2000 \mathrm{rpm}$ for 10 minutes. $50 \mu 1$ of cell pellet was on glass slide; air dried for 10 minutes and fixed in methanol.

Hematoxylin and eosin: Fixed slides were dehydrated in descending grades of ethanol two changes of one minute each. Slides 
were then immersed in filtered hematoxylin stain for 3 minutes and rinsed twice in distilled water. Slides immersed in filtered eosin stain for 5 seconds were washed with distilled water. Dried slides were immersed in xylene, mounted with Canada balsam and covered cover slips and left to dry.

Photomicrography and cytological evaluation: Fourteen microscopic fields of each slide were photomicrographed (oil immersion), by a digital video camera. Field selection was based on the presence of highest number of apoptotic cells. The photomicrographs were then evaluated for the presence of morphological criteria of apoptosis.

\section{Results}

Cytotoxicity assay; Bee venom inhibited growth of cancer cell lines in a concentration-dependent manner (viability\% of cancer cells decreased with increased concentration). Magnitude of the inhibitory effect of bee venom alone was stronger against colon cancer (Caco2) and larynx cancer (HepG2) cells than breast cancer (MCF-7) cell lines (Fig. 2a), Susceptibility of cancer cell lines (Hep-2, MCF-7 \& Caco2) towards nanoparticles after $48 \mathrm{hrs}$ (Fig. 2b). The viability\% was concentration and cell line dependent. The $\mathrm{IC}_{50}$ values for BV \& BV loaded nanoparticles on cancerous cell lines (CaCO-2, HEp-2 \& MCF-7). IC I $_{50}$ values for BV were $9.2,8.11 \& 10.70 \mu \mathrm{g} / \mathrm{ml}$ for CaCO-2, HEp-2 \& MCF-7 cell lines, respectively. But, $\mathrm{IC}_{50}$ value of $\mathrm{BV}$ loaded nanoparticles recorded 7.7, $8.6 \& 8.0588 \mu \mathrm{g} / \mathrm{ml}$ for CaCO-2, HEp$2 \&$ MCF-7 cell lines, respectively (Tab. 1). All cancer cells lines were sensitive to bee venom, empty and bee venom nanoparticles. The morphology of different types of cancer cell lines was investigated under inverted microscope. In all types of cancer cell lines, control (untreated) cells were well adherent, homogeneously distributed in the culture field exhibiting a polygonal shape with distinct boundaries and homogenous cellular contents. On the other hand, morphological observations of treated cancer cells from all cell lines at the higher concentrations of tested materials (BV and BV loaded nanoparticles) showed destruction of cell sheet, cell shrinkage, rupturing and detaching from the surface of tissue culture (Figs, 3, 4\& 5).

Histopathological examination: In all cell lines, control (untreated) cells they were regular cells with regular cellular and nuclear membranes and hyperchromatic nuclei (Figs. 6a; 7a \& 8a). Cancer cells lines treated with $\mathrm{IC}_{50}$ of BV showed Shrunken apoptotic cell (black arrow), peripheral condensation of chromatin (Yellow arrow) and nuclear fragmentation (red arrow)(Fig. 6b), apoptotic bodies (black arrows) and necrotic cell debris (yellow arrows) (Fig. 7b) and shrunken apoptotic cells with irregular cellular and nuclear membranes (Yellow arrows) and peripheral condensation of chromatin (Red arrow), Swollen necrotic cell with swollen nucleus (black arrows) (Fig. 8b). Cells treated with $\mathrm{IC}_{50}$ of $\mathrm{BV}$ loaded NPs showed small shrunken apoptotic cells (yellow arrows) and peripheral chromatin condensation (black arrow) (Fig: 6c), apoptotic shrunken cells with shrunken nuclei (green arrow). Some cells were irregular (red arrows) and nuclear membranes (black arrows) and peripheral condensation of chromatin (orange arrow) (Fig. 7c) and apoptotic cells with peripheral chromatin condensation (yellow arrows) and nucleolar segregation (ted arrow) (Fig. 8c).

Table 1: $\mathrm{IC}_{50}$ of BV \& BV loaded chitosan nanoparticles on different cancer cell lines (CaCO-2, HEp-2\& MCF-7)

\begin{tabular}{|l|l|l|}
\hline Tested material & Cell line & $\mathrm{IC}_{50}(\mu \mathrm{g} / \mathrm{ml})$ \\
\hline \multirow{4}{*}{$\mathrm{BV}$} & $C a C O-2$ & 9.2 \\
\cline { 2 - 3 } & $H E p-2$ & 8.11 \\
\cline { 2 - 3 } & $M C F-7$ & 10.70 \\
\hline \multirow{4}{*}{ BV loaded NPs } & $C a C O-2$ & 8.7 \\
\cline { 2 - 3 } & $H E p-2$ & 7.3 \\
\cline { 2 - 3 } & $M C F-7$ & 10 \\
\hline
\end{tabular}




\section{Discussion}

Several parameters affect the cytotoxic profile of CS-NPs, such as their size, surface properties and degree of deacetylation (46\%-88\%) (Loh et al, 2010). Results of the present study showed that BV loaded chitosan nanoparticles have a good anti proliferative effects against the studied cell lines, where HEp-2 cells were more susceptible to BV loaded nanoparticles than MCF-7. These results agreed with Saha et al. (2014) who stated that cytotoxicity of gold nanoparticles (GNPs) conjugated with a protein toxin from the Indian cobra Najakaouthiavenom (NKCT1) on leukemic cells (U937 and K562) was more obvious than native NKCT1. Also, N-succinyl chitosan nanoparticles conjugated with lipid showed better antitumor effect on K562 cells (Yang et al, 2009; Luo et al, 2010). In the same manner, cisplatin and cisplatin loaded chitosan nanoparticles exerted cytotoxic effect on HeLa cells in a dose dependent manner. The cytotoxic effect of cisplatin loaded nanoparticles is comparable to that of cisplatin alone (Uztüzün et al, 2015). Also, curcumin-loaded alginate nanoparticles (CS-ALG-NPs) displayed significant antitumor activity compared with the free curcumin (Ahmadi et al, 2017). In the same regard, synthesized ethanolic extract of Gymnema sylvestre leaves loaded chitosan nanoparticles (GSCNPs) and Cinnamomum zeylanicum bark extract loaded chitosan nanoparticles (CZCNP) exhibited dose-dependent cytotoxicity against human cervical cancer ( $\mathrm{SiHa}$ ) cell line, with inhibitory concentration $\left(\mathrm{IC}_{50}\right)$ values of $102.17 \mu \mathrm{g} / \mathrm{ml}, 87.75 \mu \mathrm{g} / \mathrm{ml}, 132.74 \mu \mathrm{g} / \mathrm{ml}$ and $90.35 \mu \mathrm{g} / \mathrm{ml}$ for Gymnema sylvestre (GS) leaf extract, GSCNPs, CZBE and CZCNPs, respectively (Sujima et al, 2016). Moreover, it has been observed that CS-NPs of a molecular weight of $10-213 \mathrm{kDa}$ at a size of $110-390 \mathrm{~nm}$ and degree of deacetylation; 46\%-88\% show comparable cytotoxicity profiles against A549 (human adenocarcinoma) cells with cell viability generally not affected by sample concentrations lower than $740 \mu \mathrm{gml}-1$ (Ma and Lim, 2003).

In contrast, this was different when using the MGC803 human gastric carcinoma cell line where the $\mathrm{IC}_{50}$ value was 16.2 and 5.3 $\mu$ gml-1 after $24 \mathrm{~h} \& 48 \mathrm{~h}$, respectively, in incubation with CS with a size of $65 \mathrm{~nm}$ and high charges of $51 \mathrm{mV}$ (Qi et al, 2005). Treatment of liver cancer cell line (HepG2) with different concentrations of $150 \mathrm{~nm}$ diameter chitosan nanoparticles (CS-NPs) did not show alteration of cell morphology after $24 \mathrm{~h}$ of cell exposure. Also, when cells were treated with $100 \mu \mathrm{gml}-1$ of CS-NPs, $12 \%$ of them were killed and $\mathrm{IC}_{50}$ reached 239 $\mu \mathrm{gml}-1$ after $48 \mathrm{~h}$ of cell exposure (Lotfy et $a l, 2016)$. In this regard, cytotoxicity of 40 $\mu \mathrm{M}$ ferulic acid-loaded chitosan nanoparticles (FA/CS-TPP NPs) against ME-180 cervical cancer cell lines was found to be higher as compared to $40 \mu \mathrm{M}$ native FA (Panwar et al, 2016).This indicates that small size, high positive charges and the type of biologically interacting cells and cellular uptake dramatically affect the cytotoxic effect of CS-NPs.

There are two main strategies by which chemotherapeutic agents are capable of exerting their effect: (1) induction of apoptosis and (2) cell cycle inhibition. Many of the compounds act at multiple steps in the cell cycle, and their effects may be cytostatic or cytotoxic, depending on the cell cycle status of target cells (Shapiro and Harper, 1999).

Apoptosis plays an important role in cell cycle. In this context, the present study indicated that at $\mathrm{IC}_{50}$ concentrations of the $\mathrm{BV}$ and BV loaded nanoparticles induced apoptosis in treated cancerous cells under study. The morphological changes of accompanied with apoptosis ranged from the membrane blebbing, cell shrinkage, nuclear chromatin condensation, shape irregularity, apoptotic bodies in late stage, nucleolar fragmentation, shrunken nucleus and some necrotic features, while control cells showed normal pathway of mitotic divisions in the form of obvious cell membranes and nucleus, when stained using Hematoxylin and Eosin (H\&E) 
and visualized using light microscope. Literature reports that chitosan nanoparticles owing to their positive surface charges adsorb with a high affinity onto negatively charged tumor cell membrane (Qi et al, 2005).

In the present investigation, BV loaded CSNPs would have bind to the tumor cell membrane via electron interactions, entered the cell through endocytosis and released the encapsulated BV into cytosol (endosomal burst). Due to increased bioavailability, BVmay exhibit its antitumor effect through up regulation of $\mathrm{P}_{53}$ and $\mathrm{Bax}$ and down regulation of $\mathrm{Bcl} 2$ genes which would eventually lead to cell death. Chitosan nanoparticleconjugated bee venom preferentially delivered into the nucleus inside the cells for eliciting a better therapeutic effect than native bee venom, where chitosan can escape the endosomes offering high potential for nuclear delivery. Molecular entry into the nucleus occurs through the nuclear pore complexes; the efficiency of which is dependent on NP size and the presence of nuclear localization sequence (NLS) (Tammam et al, 2015). The above-mentioned results agreed with that of another study who found that chitosan enveloped ferulic acid (FA) nanoparticles induced apoptotic morphological changes such as cytoplasmic remnants and damaged wrinkled cells in human cervical cancer cell line (ME-180)when visualized using scanning electron microscopic and fluorescent microscopic techniques (Panwar et al, 2016). Besides, cisplatin and cisplatin loaded chitosan nanoparticles exert apoptotic and necrotic effects on HeLa cells in a dose dependent manner. Apoptotic indexes generated from caspase-3 staining and double staining was compatible and found as $60 \pm 5 \%, 53 \pm 4 \%$ for cisplatin and cisplatin loaded nanoparticles, respectively, while the necrotic index was $64.2 \pm 3 \%, 60.3 \pm 2 \%$ for cisplatin and cisplatin loaded nanoparticles (Uztüzün et al, 2015). Ferulic acid (FA) from Partheniumhystero-phorus and FA encapsulated nanofibers were found to exhibit anticancer potential against different cancer cell lines
(Panwar et al, 2016). Also, curcuminloaded NPs significantly suppressed proliferation and promoted the induction of apoptosis in human cervical epithelioid carcinoma cancer cells (Ahmadi et al, 2017). Cell apoptosis study revealed that Paclitaxel chitosan nanoparticles (PTX-CS-NP) treatment resulted into enhanced (almost double) late cell apoptosis than native paclitaxel. Hence the developed nanoparticulate formulation resulted into improved anticancer efficacy of paclitaxel (Gupta et al, 2017). Similar results were obtained in case of CNPs that used as Tamoxifen carriers against breast cancer cells (Vivek et al, 2013). Also, it was reported that an enhanced rate of apoptosis by PLGA 50-50 nanoparticles against Glioma (U87MG) and breast adenocarcinoma (MCF-7) cell lines occurred (Nair et al, 2011).

\section{Conclusion}

BV loaded NPs exhibited a good cytotoxic activity. The surface charge of chitosan was the major factor in the cytotoxic activity due to the electrostatic ionic interaction between the negatively charged groups of tumor cells and the positively charged amino groups of chitosan in addition to cytotoxic effect of bee venom itself, which strongly suggest that eco-friendly CNP-based drugs could be developed appropriately for the treatment of cancer cells without any effects. BV loaded NPs offer a promising new approach to drug delivery in the treatment of cancer. Nanocapsulated bee venom showed anticancer potential than BV itself. Also, Nano capsulation could enhance the anticancer potential that was cell type and concentration dependent manner. Further study should focus on possible in vivo use of BV loaded NPs.

\section{References}

Abdel-Rahman, RZ, Mohamad, HM, Morsy, ATA, Morsy, TA, 2015: Allergic reactions caused by venom of hymenopterous stinging insects and the role of health care workers. J. Egypt. Soc. Parasitol.. 45, 2: 403-12

Ahmadi, F, Ghasemi-Kasman, M, Ghasemi, S, Gholamitabar Tabari, M, Pourbagher, R, et al, 2017: Induction of apoptosis in HeLa can- 
cer cells by an ultrasonic-mediated synthesis of curcumin-loaded chitosan-alginate-STPP nanoparticles. Int. J. Nanomed.12:8545-56.

Avadi, MR, Sadeghi, AM, Dounighi, MN, Abedin, S, Atyabi, F, et al, 2010: Preparation and characterization of insulin nanoparticles using chitosan and Arabic gum with ionic gelation method. Nanomedicine 6, 1:58-63.

Calderon, LA, Sobrinho, JC, Zaqueo, KD, de Moura, AA, Grabner, AN, 2014: Antitumoral activity of snake venom proteins: New trends in cancer therapy. Biomed. Res. Int. 2014: 203639 doi: 10.1155/2014/203639

Dounighi, NM, Mehrabi, M, Avadi, MR, Zolfagharian, H, 2015: Preparation, characterization and stability investigation of chitosan nanoparticles loaded with the Echis carinatus snake venom as a novel delivery system. Arch. Razi Inst. 70, 4:269-77.

Gupta, RB, 2006: Fundamentals of drug nanoparticles. In: Nanoparticle Technology for Drug Delivery. Gupta, RB, Kompella, UB (eds.). Taylor \& Francis Group, New York.

Gupta, U, Sharma, S, Khan, I, Gothwal, A, Sharma, AK, et al, 2017: Enhanced apoptotic and anticancer potential of paclitaxel loaded biodegradable nanoparticles based on chitosan Int. J. Biol. Macromo. 98:810-9

Jain, KK, 2008: Nanopharmaceuticals. In: The Handbook of Nanomedicine. Social Science Print Books, Humana Press

Jemal, A, Bray, F, Center, MM, Ferlay, J, Wa rd, E, et al, 2011: Global Cancer Statistics. CA Cancer J. Clin. 61, 2:69-90.

Li-Feng, Qi, Zi-Rong, Xu, Yan, Jiang, LX, Han, XY, 2005: In vitro effects of chitosan nanoparticles on proliferation of human gastric carcinoma cell line $\mathrm{MGC}_{803}$ cells. Wld. J. Gastroenterol. 11, 33:5136-41.

Liu, X, Chen, D, Xie, L, Zhang, R, 2002: Effect of honey bee venom on proliferation of K1735M2 mouse melanoma cells in-vitro and growth of murine B16 melanomas in-vivo. J. Pharm. Pharmacol. 54, 8:1083-9.

Loh, JW, Yeoh, G, Saunders, M, Lim, LY, 2010: Uptake and cytotoxicity of chitosan nanoparticles in human liver cells. Toxicol. Appl. Pharmacol. 249:148-157.

Loutfy, SA, Alam El-Din, HM, Elberry, MH, Nanis G Allam, NG, et al, 2016: Synthesis, characterization and cytotoxic evaluation of chitosan nanoparticles: in vitro liver cancer model. Adv. Adv. Nat. Sci.: Nanosci. Nanotechnol. Vie- tnam Academy of Science \& Technology

Luo, H, Li, J, Chen, X, 2010: Antitumor effect of N-succinyl-chitosan nanoparticles on K562 cells. Biomed. Pharmacother. 64, 8:521-6.

Ma, Z, Lim, LY, 2003: Uptake of chitosan and associated insulin in Caco- 2 cell monolayers: A comparison between chitosan molecules and chitosan nanoparticles. Pharmaceut. Res. 20: 1812-9.

Marei, NH, El-Samie, EA, Salah, T, Saad, G R, Elwahy, AH, .2016: Isolation and characterization of chitosan from different local insects in Egypt. Int. J. Biol. Macromol. 82:871-7.

Mastropietro, G, Tiscornia, I, Perelmuter, K, Astrada, S, Fogolín, MB, 2015: HT-29 and Caco-2 reporter cell lines for functional studies of nuclear factor kappa B activation. Mediat. Inflamm. : 860534 doi: 10.1155/ 2015/860534

Mokarram RA, Alonso, MJ, 2006: Preparation and evaluation of chitosan nanoparticles containing Diphtheria toxoid as new carriers for nasal vaccine delivery mice. Archives of Razi Inst. 61, 1:13-25.

Nair, KL, Jagadeeshan, S, Nair, SA, Kumar, GS, 2011: Biological evaluation of 5-fluorouracil nanoparticles for cancer chemotherapy and its dependence on the carrier, PLGA. Int. J. Nanomedicine 6: 1685-97.

Panwar, R, Sharma, AK, Kaloti, M, Dutt, D, Pruthi, V, 2016: Characterization and anticancer potential of ferulic acid-loaded chitosan nanoparticles against ME-180 human cervical cancer cell lines. Appl. Nanosci. 6, 6:803-13.

Park, HJ, Lee, SH, Son, DJ, Oh, KW, Kim, K H, et al, 2004: Antiarthritic effect of bee venom: inhibition of inflammationmediator generation by suppression of NF kappa B through interaction with the p50 subunit. Arthr. Rheum. 50, 11: 3504-15.

Park, HJ, Son, DJ, Lee, CW, Choi, MS, Lee, US, et al, 2007: Melittin inhibits inflammatory target gene expression and mediatorgeneration via interaction with IкB kinase. Biochem. Pharmacol. 73, 2:237 47.

Saha, PP, Bhowmik, T, Dasgupta, AK, Gomes, A, 2014): In vivo and in vitro toxicity of nanogold conjugated snake venom protein toxin GNP-NKCT1. Toxicol. Rep. 2; 1:74-84.

Sarei, F, Dounighi, NM, Zolfagharian, H, Khaki, P, Bidhendi, MS, 2013: Alginate Nanoparticles as a Promising Adjuvant and Vaccine Delivery System. Indian J. Pharm. Sci. 75, 4:442-9. Shahbazi, MA, Hamidi, M, Peymani, P, 2008: 
Interaction of chitosan, a natural polymer used in Nanodrug /gene delivery, with non-steroidal anti-inflammatory drugs (NSAIDs). Internet J. Nanotech. 2, 2:1-7.

Shapiro, GI, Harper, JW, 1999: Anticancer drug targets: Cell cycle and checkpoint control. J. Clin. Invest. 104, 12:1645-53.

Son, DJ, Lee, JW, Lee, YH, Song, HS, Lee, C $\mathrm{K}$, et al, 2007: Therapeutic application of antiarthritis, pain-releasing, and anti-cancer effects of bee venom and its constituent compounds. Pharmacol. Ther. 115, 2:246-70.

Sujima, A, Velmurugan, P, Lee, JH, Oh, BT, Venkatachalam, P, 2016: Biomolecule-loaded chitosan nanoparticles induce apoptosis and molecular changes in cancer cell line (SiHa). Int. J. Biol. Macromol. 88:18-26.

Tammam, SN, Hassan ME. Azzazy, HME, Breitinger, HG, Lamprecht, Alf, 2015: Chitosan nanoparticles for nuclear targeting; the effect of nanoparticle size and nuclear localization sequence density. Mol. Pharma. 12, 12:4277-89.

Tiyaboonchai, W, 2003: Chitosan nanoparticles: A promising system for drug delivery. Naresuan Univ. J. 11, 3:51-66.

Uztüzün, SO, Tandogan, N, Turk, M, Karahan, S, Suludere, Z, 2015: The Apoptotic and Necrotic Effects of Cisplatin Loaded Chitosan Nanoparticles on Hela cell lines. Acad. J. Cancer
Res. 8, 4:58-68.

Van der Lubben, IM, Verhoef, JC, Borchard, G, Junginger, HE, 2001a: Chitosan for mucosal vaccination. Adv. Drug Deliv. Rev. 52, 2: $139-44$.

Van der Lubben, IM, Verhoef, JC, Borchard, G, Junginger, HE, 2001b: Chitosan and its derivatives in mucosal drug and vaccine delivery. Euro J. Pharma. Sci.14, 3:201-7.

Vila, A, Sánchez, A, Janes, K, Behrens, I, Kissel, T, 2004: Low molecular weight chitosan nanoparticles as new carriers for nasal vaccine delivery in mice. Eur. J. Pharm. Biopharm. 57, 1: 123-31.

Vivek, R, Nipun Babu, V, Thangam, R, Subramanian, KS, Kannan, S, 2013: pH-responsive drug delivery of chitosan nanoparticles as Tamoxifen carriers for effective anti-tumor activity in breast cancer cells. Colloids Surf. B: Biointerfaces 1, 111:117-23.

Xu, Y, Du, Y, 2003: Effect of molecular structure of chitosan on protein delivery properties of chitosan nanoparticles. Int. J. Pharmaceut. 250, 1:215-26.

Yang, X, Koh, CG, Liu, S, Pan, X, Santhanam, R, et al, 2009:Transferrin receptortargeted lipid nanoparticles for delivery of antisense oligodeoxyribonucleotide against $\mathrm{Bcl}-2$. Mol. Pharm. 6, 1:221-30.

\section{Explanation of figures}

Fig. 1: Schematic representation of chitin and chitosan extraction process

Fig. 2: Relationship between concentrations and residual cell viability percentage of different cancer cell lines post treatment with: (a) BV and (b) BV loaded nanoparticles (BV loaded NPs)

Fig. 3: Morphological characteristics of unstained treated and untreated CaCO-2 cells (A): untreated cells, (B): Toxic effect of bee venom. (C): Toxic effect of Empty nanoparticles. (D): Toxic effect of BV loaded nanoparticles.

Fig. 4: Morphological characteristics of unstained treated and untreated HEp-2 cells(A): untreated cells, (B): Toxic effect of bee venom. (C): Toxic effect of Emptynanoparticles. (D): Toxic effect of BV loaded nanoparticles.

Fig. 5: Morphological characteristics of unstained treated and untreated MCF-7 cells (A): untreated cells, (B): Toxic effect of bee venom. (C): Toxic effect of Empty nanoparticles. (D): Toxic effect of BV loaded nanoparticles.

Fig. 6: Histopathological observations of CaCO-2 cells: (a) control cells; (b) cells treated with $\mathrm{IC}_{50}$ concentration of $\mathrm{BV}$; and (c) cells treated with $\mathrm{IC}_{50}$ concentration of BV loaded NPs

Fig 7: Histopathological observations of HEp-2 cells: (a) control cells; (b) cells treated with $\mathrm{IC}_{50}$ concentration of BV; and (c) cells treated with $\mathrm{IC}_{50}$ concentration of BV loaded NPs

Fig 8: Histopathological observations of MCF-7cells: (a) control cells; (b) cells treated with $\mathrm{IC}_{50}$ concentration of BV; and (c) cells treated with $\mathrm{IC}_{50}$ concentration of BV loaded NPs

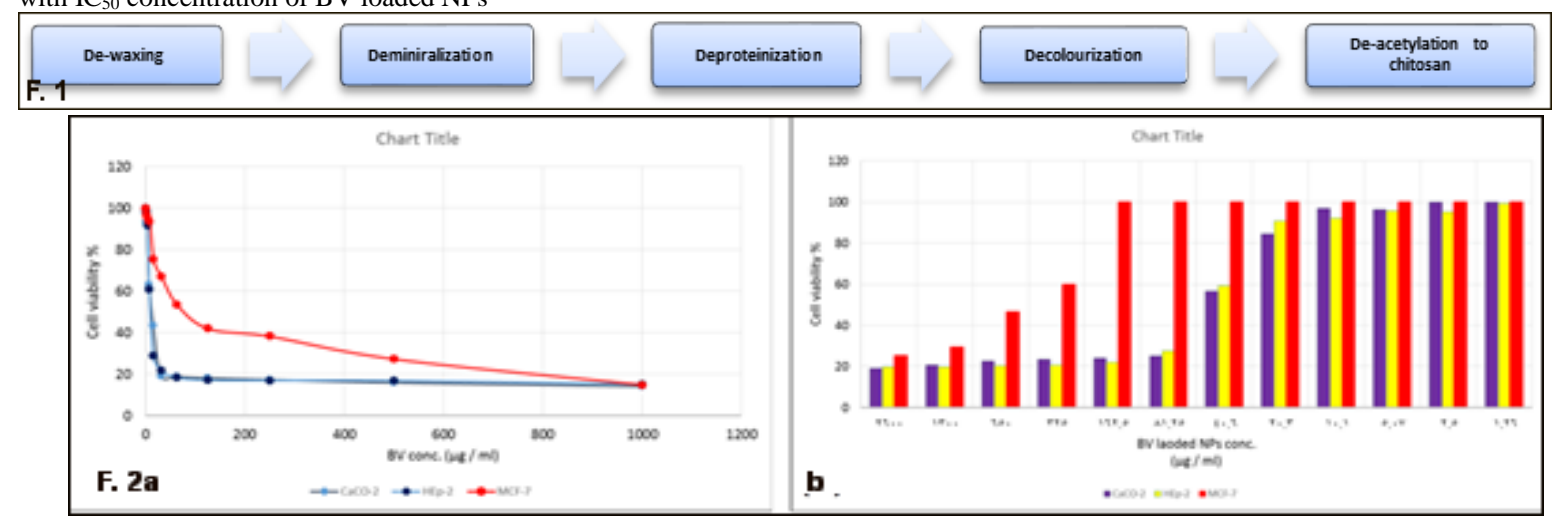




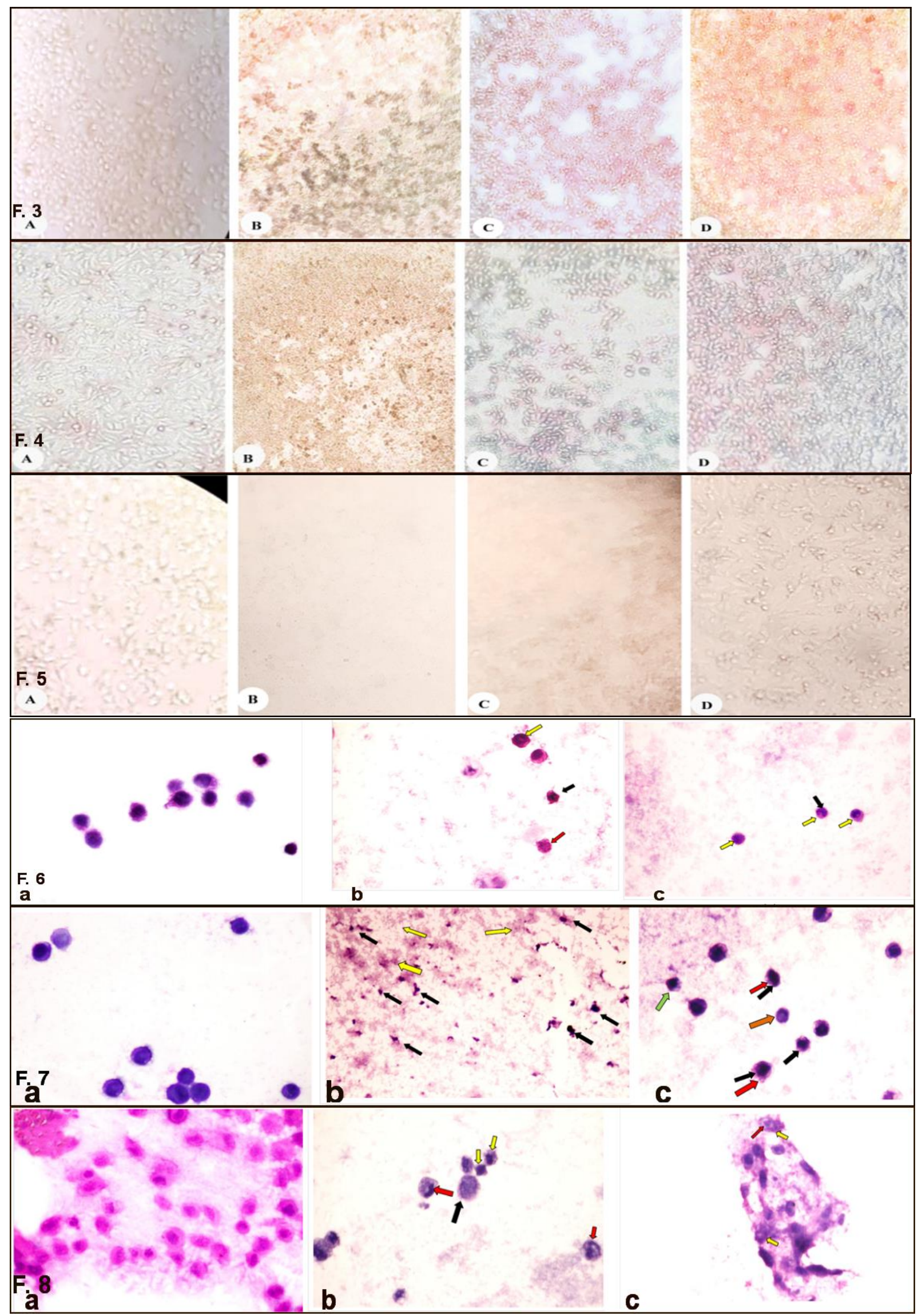

